\title{
Crop photosynthesis for the twenty-first century
}

\author{
Marian Brestic ${ }^{1} \cdot$ Xinghong Yang $^{2} \cdot{\text { Xiangnan } \mathrm{Li}^{3} \cdot \text { Suleyman I. Allakhverdiev }}^{4}$
}

Published online: 21 October 2021

(c) The Author(s), under exclusive licence to Springer Nature B.V. 2021

Energy from the sun supports all life on our planet. This lifegiving energy is transformed by the photosynthetic process in plants into forms of energy that can be used by other organisms. Humans, through crops, can obtain all essential substances necessary for life. We depend on plant life, photosynthesis, and the complex chain of metabolic reactions; however, the photosynthetic process converts only approximately $5 \%$ of the energy that plants receive into biomass (Zhu et al. 2008). For decades, we have been trying to understand how photosynthetic organisms work, how they adapt to changes in the environment, and how plant photosynthesis controls crop yields.

However, evidence from recent decades has also shown that the Earth's human population and economic growth contribute to the intensification of the greenhouse effect and global warming. As a result, agricultural and surrounding ecosystems will be affected. The consequences will range from disruption of ecosystem services and loss of biodiversity to a decline in crop production and quality at a regional level. Additionally, climate extremes; drought, high temperatures, and increases in salinity, etc. are factors that are clearly damaging plants and leading to consequences in terms of food insecurity.

The twentieth century was a period of economic growth, as well as a period of intense study of plant mechanisms and of the development of methodology in plant research (Nagy and Garab 2021), which has improved the performance of cultivated species and, consequently, increased

Suleyman I. Allakhverdiev

suleyman.allakhverdiev@gmail.com

1 Department of Plant Physiology, Slovak University of Agriculture, Nitra, Slovak Republic

2 Department of Plant Physiology, College of Life Sciences, Shandong Agricultural University, Taian, China

3 Northeast Institute of Geography and Agroecology, Chinese Academy of Sciences, Changchun, China

4 K.A. Timiryazev Institute of Plant Physiology, Russian Academy of Sciences, Moscow, Russia food production. As part of the green revolution, plant scientists primarily use conventional techniques to improve yields, for instance, producing plants with shorter stalks and increased seed production (Srinivasan et al. 2017; Adamidis et al. 2019; Simkin et al. 2019; Yan et al. 2021).

The sustainability of crop production and the implications of the latest scientific knowledge on plant regulatory mechanisms must also be among the most important targets for innovation in photosynthesis research (Allakhverdiev 2020a,b; Ritchie et al. 2021). Additionally, along with climate change challenges, the problem of arable land shortages has also arisen. Clearing new lands for crop production may have a negative impact on unique environments, and the use of low-quality land requires additional approaches to obtain the required yields. Therefore, crop yields must be improved without increasing the amount of cultivatable land.

Taking into consideration that a given plant variety will perform differently according to geography and season, studies of genetic changes may significantly contribute to plant performance and crop improvement. The discovery of dwarfing genes delivered a principal genetic source for the development of high-yielding varieties of wheat and rice worldwide. In Arabidopsis thaliana, tobacco, and tomato, the overexpression of sedoheptulose-1,7-bisphosphatase results in an increase in both photosynthetic carbon assimilation and biomass yield. As another approach to increase crop productivity, cyanobacterial enzymes are expressed in higher plants, causing an enhanced rate of growth and photosynthetic $\mathrm{CO}_{2}$ fixation (Miyagava et al. 2001; Ding et al. 2016; Simkin et al. 2019; Chen et al. 2021).

Measurements of photosynthetic parameters have become the basis for research on genetic resources, the breeding of modern varieties, and the improvement of technological processes in the cultivation of crops worldwide.

Photosynthesis is the primary determinant of crop yield, but plants absorb more solar light than they can effectively use. There are suggested options to improve the photosynthetic machinery of plants by inserting the machinery from a purple photosynthetic bacterium and by the replacement of chlorophyll $a$ with chlorophyll $d$ from the cyanobacterium 
Acaryochloris marina. Thus, biotechnology can be a powerful tool for redesigning the production of crop plants with higher yields, which can bring humanity closer to solving future agricultural crises.

The development of science is not uniform; it depends not only on leaps in knowledge in related disciplines but also on the accumulation of information. It is therefore important that the topic of photosynthesis and production be addressed worldwide so that scientific knowledge is transferred to farmers and breeders, especially in countries with large population growth.

Over the past decades, the global demand for crops for food and fuel production has significantly increased to try to keep pace with the growing population. Advances in agricultural approaches and classical breeding have produced higher-yielding plant varieties to magnify plant architecture and light-capture efficiency. From this point of view, it is extremely important to support photosynthesis research in developing countries.

In the twenty-first century, we will have to face a more difficult task- to intensify our understanding of plant regulatory mechanisms and to construct effective applications to improve plants for a rapidly changing environment. However, by 2050 , the global population is estimated to increase from its current 7.6 billion to 9.7 billion, and consequently, the recently plateaued yields of the major crops must be enhanced to maintain the food supply. The prospect of world hunger looms again. Photosynthesis is influenced by multiple environmental factors, including high temperature, drought, salinity, high and fluctuating light, mineral nutrition, and $\mathrm{CO}_{2}$ concentration (Brestic et al. 2018; Ferroni et al. 2020; Ibrahimova et al. 2021; Li et al. 2021). The question of how plants grow under changes in these environmental conditions and how photosynthesis optimization occurs are some of the most important and interesting questions in studying plant growth, for if we are able to quantify the optimal environmental conditions that maximize photosynthesis, they can be employed in controlled environments to increase crop productivity (Aliyeva et al. 2020; Hussain et al 2021; Mishra et al. 2021; Yan et al. 2021). We want to improve the structural and functional properties of the photosynthetic apparatus so that modern varieties are more efficient and effective in the use of water and mineral nutrition resources and more tolerant to environmental changes.

Different ploidy levels of chromosomes probably play an important regulatory role in the photosystems and antioxidative systems of plants (Mao et al 2018; Chovancek et al. 2021). Despite much successful research, there is still a lack of information on how plants can more efficiently transform solar energy and better fix $\mathrm{CO}_{2}$, how plants respond to combined environmental stress factors, and how they will be able to cope with the consequences of climate change in the twenty-first century ( $\mathrm{Li}$ et al. 2019). Therefore, there is a great necessity for reviving research into the ecophysiology of photosynthesis.

Research into photosynthesis in model plant organisms is extremely important in light of new knowledge of mechanistic research (Shimakawa and Miyake 2019; Kohga et al. 2021), but the results of agricultural crop research are particularly important and directly applicable in practice (Petrov et al 2018; Ramazan et al 2021).

The aim of this special issue is to help elucidate the current progress of this research by providing a combination of reviews and original research articles.

This special issue focuses on a wide range of issues that can initiate new approaches, deeper research, new applications, and the motivation to focus plant research more on the unique process of photosynthesis.

As the only yield determinant that is not close to its biological limits, photosynthesis gives us a great opportunity to improve crop yields. Thus, understanding the mechanism of its manipulation is necessary to make a step toward the solution of global food security. We assume that the twenty-first century will be a period of intense photosynthetic research.

Acknowledgements We thank all the authors of the manuscripts for this issue. Additionally, we thank Terry Bricker (Editor-in-Chief) for giving us this opportunity, Carola Vermeeren and Matthew Cheng for their invaluable supports.

\section{References}

Adamidis GC, Cartar RV, Melathopoulos AP et al (2019) Pollinators enhance crop yield and shorten the growing season by modulating plant functional characteristics: a comparison of 23 canola varieties. Sci Rep 9:14208. https://doi.org/10.1038/ s41598-019-50811-y

Aliyeva NK, Aliyeva DR, Suleymanov SY, Rzayev FH, Gasimov EK, Huseynova IM et al (2020) Biochemical properties and ultrastructure of mesophyll and bundle sheath thylakoids from maize (Zea mays) chloroplasts. Funct Plant Biol 47:970-976. https://doi.org/ 10.1071/FP20004

Allakhverdiev SI (2020a) Editorial for the special issue on photosynthesis and hydrogen energy research for sustainability-2019. Photosynth Res 146:1-3. https://doi.org/10.1007/s11120-020-00764

Allakhverdiev SI (2020b) Optimising photosynthesis for environmental fitness. Funct Plant Biol 47:iii-vii. https://doi.org/10.1071/FPv47 n11_FO

Brestic M, Zivcak M, Hauptvogel P, Misheva S, Kocheva K, Yang X, Li X, Allakhverdiev SI (2018) Wheat plant selection for high yields entailed improvement of leaf anatomical and biochemical traits including tolerance to non-optimal temperature conditions. Photosynth Res 136(2):245-255. https://doi.org/10.1007/ s11120-018-0486-Z

Chen M, Liang F, Yan Y, Wang Y, Zhang Y, Tian J, Jiang C, Zhang W (2021) Boll-leaf system gas exchange and its application in the analysis of cotton photosynthetic function. Photosynth Res. https://doi.org/10.1007/s11120-021-00856-

Chovancek E, Zivcak M, Brestic M, Hussain S, Allakhverdiev SI (2021) The different patterns of post-heat stress responses in 
wheat genotypes: the role of the transthylakoid proton gradient in efficient recovery of leaf photosynthetic capacity. Photosynth Res. https://doi.org/10.1007/s11120-020-00812-0

Ding F, Wang M, Zhang S, Ai X (2016) Changes in SBPase activity influence photosynthetic capacity, growth, and tolerance to chilling stress in transgenic tomato plants. Sci Rep 6:1-14

Ferroni L, Zivcak M, Sytar O, Kovar M, Watanabe N, Pancaldi S, Baldisserotto BM (2020) Chlorophyll-depleted wheat mutants are disturbed in photosynthetic electron flow regulation but can retain an acclimation ability to a fluctuating light regime. Environ Exp Bot 178:104156. https://doi.org/10.1016/j.envexpbot.2020.104156

Hussain S, Ulhassan Z, Brestic M, Zivcak M, Zhou W, Allakhverdiev SI, Yang X, Safdar ME, Yang W, Liu W (2021) Photosynthesis research under climate change. Photosynth Res. https://doi.org/ 10.1007/s11120-021-00861-z

Ibrahimova U, Zivcak M, Gasparovic K, Rastogi A, Allakhverdiev SI, Yang X, Brestic M (2021) Electron and proton transport in wheat exposed to salt stress: is the increase of the thylakoid membrane proton conductivity responsible for decreasing the photosynthetic activity in sensitive genotypes? Photosynth Res. https://doi.org/ 10.1007/s11120-021-00853-z

Kohga H, Saito Y, Kanamaru M, Uchiyama J, Ohta H (2021) The lack of the cell division protein FtsZ induced generation of giant cells under acidic stress in cyanobacterium Synechocystis sp. PCC6803. Photosynth Res. https://doi.org/10.1007/s11120-020-00792-1

Li X, Li Y, Zhu X, Liu S (2019) Modulation of photosynthate supply by $\mathrm{CO}_{2}$ elevation affects the post-head-emergence frost-induced grain yield loss in wheat. J Agro Crop Sci 205(1):54-64. https:// doi.org/10.1111/jac.12304

Li D, Wang M, Zhang T, Chen X, Li C, Liu Y, Brestic M, Chen THH, Yang X (2021) Glycinebetaine mitigated the photoinhibition of photosystem II at high temperature in transgenic tomato plants. Photosynth Res 147:301-315. https://doi.org/10.1007/ s11120-020-00810-2

Mao H, Chen M, Su Y, Wu N, Yuan M, Yuan S, Brestic M, Zivcak M, Zhang H, Chen Y (2018) Comparison on photosynthesis and antioxidant defense systems in wheat with different ploidy levels and octoploid triticale. Int J Mol Sci 19:3006. https://doi.org/10. 3390/ijms 19103006

Miyagawa Y, Tamoi M, Shigeoka S (2001) Overexpression of a cyanobacterial fructose-1, 6-/sedoheptulose-1, 7-bisphosphatase in tobacco enhances photosynthesis and growth. Nat Biotechnol 19:965-969
Mishra M, Wungrampha S, Kumar G, Singla-Pareek PA (2021) How do rice seedlings of landrace Pokkali survive in saline fields after transplantation? Physiology, biochemistry, and photosynthesis. Photosynth Res. https://doi.org/10.1007/s11120-020-00771-6

Nagy G, Garab G (2021) Neutron scattering in photosynthesis research: recent advances and perspectives for testing crop plants. Photosynth Res. https://doi.org/10.1007/s11120-020-00763-6

Petrov P, Petrova A, Dimitrov I, Tashev T, Olsovska K, Brestic M, Misheva S (2018) Relationships between leaf morpho-anatomy, water status and cell membrane stability in leaves of wheat seedlings subjected to severe soil drought. J Agro Crop Sci 204(3):219-227. https://doi.org/10.1111/jac.12255

Ramazan S, Bhat HA, Zargar MA, Ahmad P, John R (2021) Combined gas exchange characteristics, chlorophyll fluorescence and response curves as selection traits for temperature tolerance in maize genotypes. Photosynth Res. https://doi.org/10.1007/ s11120-021-00829-z

Ritchie RJ, Sma-Air S, Limsathapornkul N, Pranama N, Nakkeaw M, Kaewnam P, Thongchumnum P, Kanjanachatee K (2021) Photosynthetic electron transport rate (ETR) in the littoral herb Launaea sarmentosa known as mole crab in Thailand. Photosynth Res. https://doi.org/10.1007/s11120-021-00826-2

Simkin AJ, Lopez-Calcagno PE, Raines CA (2019) Feeding the world: improving photosynthetic efficiency for sustainable crop production. J Exp Bot 70:1119-1140

Shimakawa G, Miyake Ch (2019) What quantity of photosystem i is optimum for safe photosynthesis? Plant Physiol 179(4):1479_ 1485. https://doi.org/10.1104/pp.18.01493

Srinivasan V, Kumar P, Long SP (2017) Decreasing, not increasing, leaf area will raise crop yields under global atmospheric change. Glob Chang Biol 23:1626-1635. https://doi.org/10.1111/gcb. 13526

Yan Y, Hou P, Duan F, Niu L, Dai T, Wang K, Zhao M, Li S, Zhou W (2021) Improving photosynthesis to increase grain yield potential: an analysis of maize hybrids released in different years in China. Photosynth Res. https://doi.org/10.1007/s11120-021-00847-x

Zhu X-G, Long SP, Ort DR (2008) What is the maximum efficiency with which photosynthesis can convert solar energy into biomass? Curr Opin Biotechnol 19:153-159. https://doi.org/10.1016/j.copbio.2008.02.004

Publisher's Note Springer Nature remains neutral with regard to jurisdictional claims in published maps and institutional affiliations. 